\title{
EFFECTS OF REMOVABLE ANTERIOR EXPANSION SCREW ON SPEECH INTELLIGIBILITY IN A GROUP OF EGYPTIAN CHILDREN
}

\author{
Adel Rashid *, Hanem El Feky*, Ahmed Abdelhamid Abdel Goad** \\ and Salwa Ahmed Abdelhady ***
}

\begin{abstract}
Aim : This study was conducted to evaluate the speech disorders that could be reported after insertion of removable anterior expansion screw appliances used for correction of anterior dental crossbite.
\end{abstract}

Materials and Methods: Fifty children with mean age (9.36 \pm 0.99 years) and diagnosed to have anterior dental crossbite. The anterior crossbite was planned to be corrected with removable anterior screw and posterior bite plane. Speech evaluation (including: articulation test and speech intelligibility test) was performed; before appliance insertion ,immediately after appliance insertion , one weeh after appliance insertion and finally after one month from appliance insertion.

Results : Before appliance insertion, all sounds were intact for the majority of the cases 42(84\%). Immediately after insertion, all the cases had difficulty in producing /s/, /s. /, /z/ sounds $(100 \%)$. After one week of insertion, majority of the cases $30(60 \%)$ still had difficulty in producing the same sounds. While, After one month of insertion, most of the cases $40(80 \%)$ had no problem in producing different sounds .

Conclusion : The speech performance while using removable anterior expansion screw for was worst immediately after placement of the appliance and 1 week respectively and improved after one month of appliance insertion.

KEYWORDS : Anterior crossbite, Speech Intelligibility,Anterior Expansion Screw

\footnotetext{
* Lecturer of Orthodontics, Faculty of dentistry, Fayoum University, Fayoum, Egypt.

** Assistant Professor of Phoniatrics and Consultant of Phoniatrics, Unit of Phoniatrics, Otorhinolaryngology Department, Faculty of Medicine, Ain Shams University Hospitals, Cairo, Egypt.

*** Lecturer of Phoniatrics and Consultant of Phoniatrics, Unit of Phoniatrics, Otorhinolaryngology Department, Faculty of Medicine, Benha University Hospitals, Benha, Egypt.
} 


\section{INTRODUCTION}

The orthodontic appliance, especially during the first few days of insertion, could create some kind of discomfort and speech difficulties which in turn could have a negative impact on patient compliance ${ }^{(1-3)}$. The orthodontic appliances are considered a foreign object in the oral cavity, specifically those which are fitting against the palate and palatal aspects of the upper anterior teeth, which in turn influence the tongue movement and eventually impede the development of such particular sounds ${ }^{(4)}$.

The most common examples of orthodontic appliances having a direct effect on speech efficiency are lingual fixed appliances ${ }^{(5-7)}$, tongue thrusting controlling appliances ${ }^{(8,9)}$, palatal expansion appliances ${ }^{(10,11)}$ and all removable appliances ${ }^{(12-14)}$.

Anterior crossbite is characterized as a situation in which their antagonists are labially obscured by one or more primary or permanent mandibular incisors (or when one or more maxillary incisors are lingual to their antagonists ${ }^{(15)}$. Crossbites in the deciduous and mixed dentitions are thought to be transmitted to the permanent dentition and may have long-term effects on the growth of the jaws and development of teeth ${ }^{(16)}$. In order to normalize the occlusion and establish conditions for normal occlusal growth, interceptive treatment is therefore always recommended.

For the correction of anterior crossbite in mixed dentition, various treatment modalities are used, including: bonding brackets to four maxillary incisors in conjunction with banding of two maxillary permanent first molars ( 2 x 4 fixed appliances), fixed acrylic inclined planes ${ }^{(17)}$, bonded resin-composite slopes ${ }^{(18)}$ and many Essix-based appliances ${ }^{(19)}$ and removable expansion sets ${ }^{(20)}$.

Removable appliances have the benefits for young patients of easier cleaning and oral hygiene treatment, the use of palatal anchorage and the ability to move a selected block of teeth ${ }^{(21)}$.

It was important to study the effects of the removable orthodontic appliances on speech intelligibility which could help the orthodontists to understand the processes underlying these distortions of speech, and to inform their patients critically about these problems and find effective solutions for them.

The evaluation of speech disorders which vary between different languages, and it appears that in patients speaking Arabic as their native language, few studies ${ }^{(4,5,6,7,10)}$ have been conducted on the effect of the fixed labial and lingual orthodontic appliances on speech and only one study ${ }^{(22)}$ have been done (has) on the effect of the removable hawely retainer on speech but there are no reported data on speech impairment after (with?) removable palatal appliances, for this reason this study was conducted.

\section{SUBJECTS AND METHODS}

\section{1- Sample size calculation:}

A power analysis was designed to have an adequate power to apply a double-sided statistical test of the null hypothesis considering no difference between both tested groups. By adopting an effect size $(\mathrm{d}=0.821)$ - calculated based on the results of

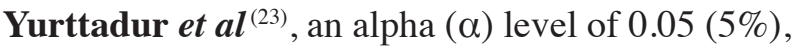
and a beta $(\beta)$ level of $0.20(20 \%)$ i.e. power $=80 \%$; the sample size (n) was predicted to be a total of (50) cases. Sample size calculation was done using $\mathrm{G}^{(*)}$ Power version 3.1.9.4

\section{2- Children:}

Fifty children (28 males (56\%) and 22 (44\%) females) with anterior dental cross bite with mean age of $(9.36 \pm 0.99$ years) Demographic data were presented in figure (1).

(*) Faul, Franz, et al. "G* Power 3: A flexible statistical power analysis program for the social, behavioral, and biomedical sciences." Behavior research methods 39.2 (2007): 175-191. 
Children included in the current study were selected from private orthodontic clinics, Benha City, Qalioubia governorate, Egypt.

All children fulfilled the following criteria: Mixed dentition stage with three or the four maxillary permanent incisors in crossbite relationship and full eruption of the four first permanent molars. All children and their parents were selected to be well cooperative. Figures (2 and 3)

\section{3- Methods}

Approval for the research proposal was obtained from Ethics Committee of the Faculty of Medicine, Benha University. Written consents were obtained from the children and their parents/guardians who agreed to participate in the study. All the clinical

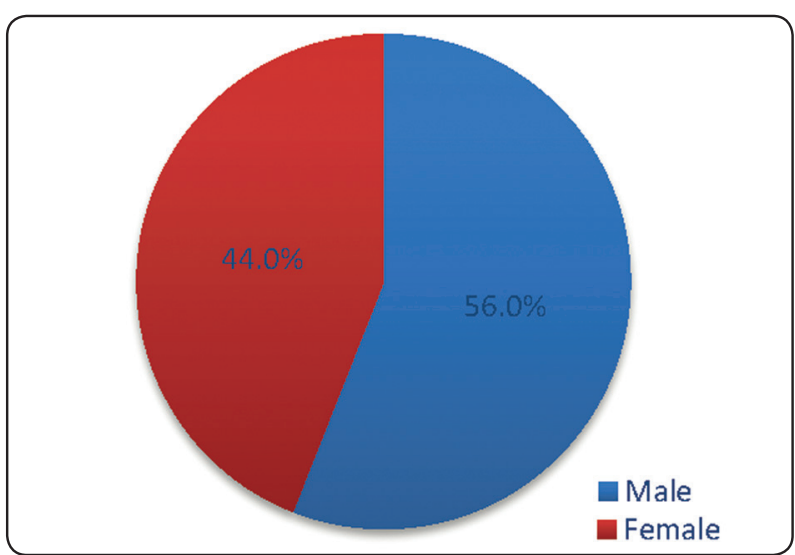

Fig. (1): Pie chart showing gender distribution

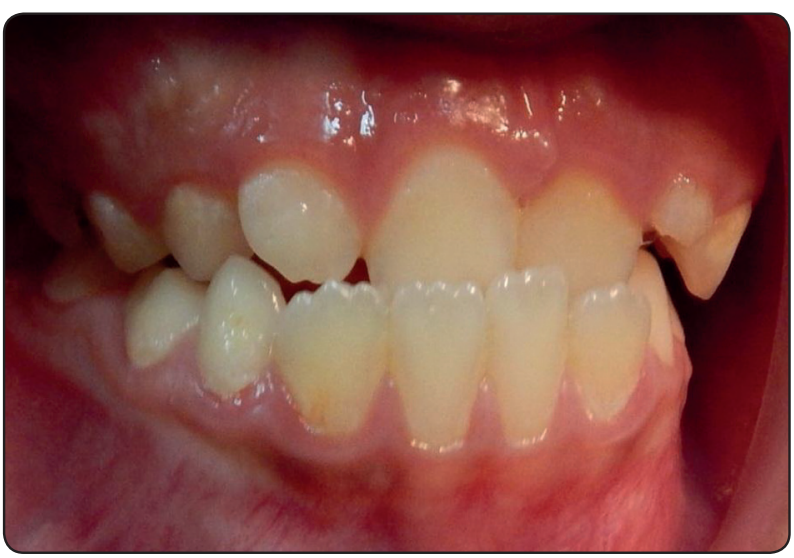

Fig. (3): Anterior dental cross bite (Oblique 45 degree view) procedures of the current study and its aim were explained to the children and their parents.

\section{A-Orthodontic Treatment:}

The anterior crossbite was planned to be corrected by removable anterior expansion screw with posterior bite planes (one dimensional screw). Figure (5)

Accurate and profound alginate impressions for both upper and lower arches were taken (Tropicalgin) (Zhermack GmbH, Germany) and study models were made with plaster. The removable appliance was fabricated using acrylic resin with bilateral occlusal coverage for the posterior teeth. One dimensional expansion screw was added anteriorly behind the maxillary permanent incisors (figure 5).

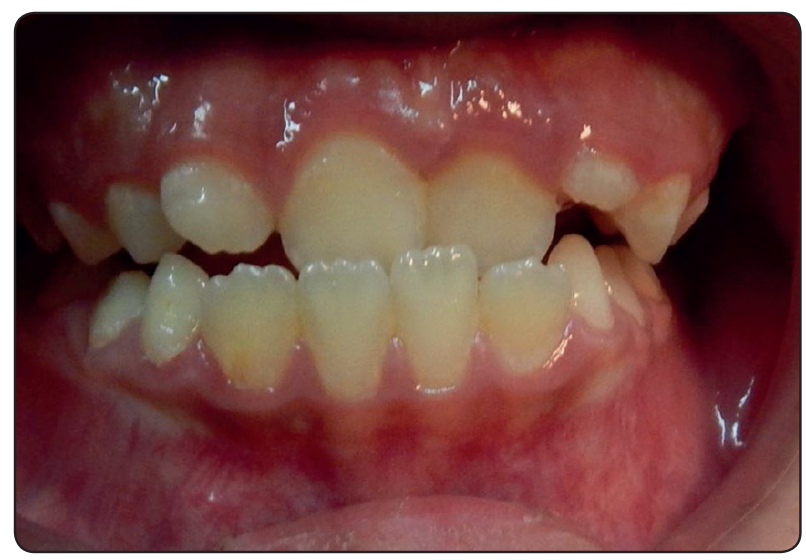

Fig. (2): Anterior dental cross bite (Frontal view)

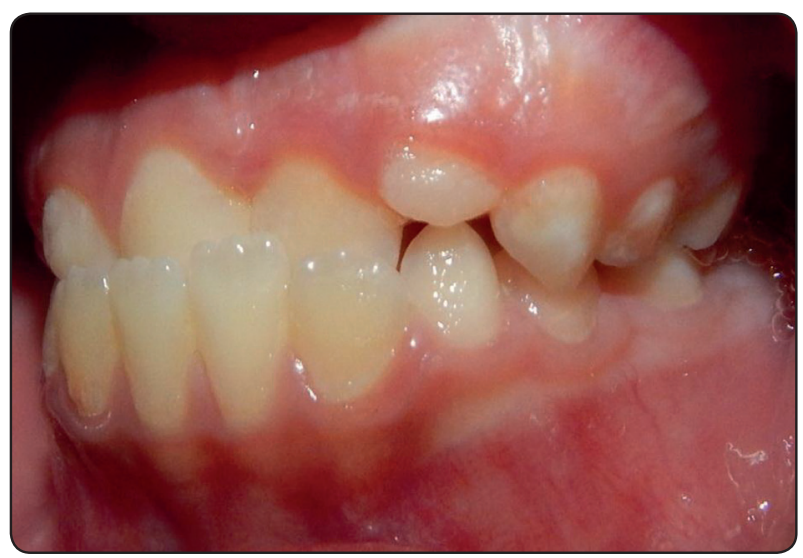

Fig. (4): Anterior dental crossbite (lateral view) 


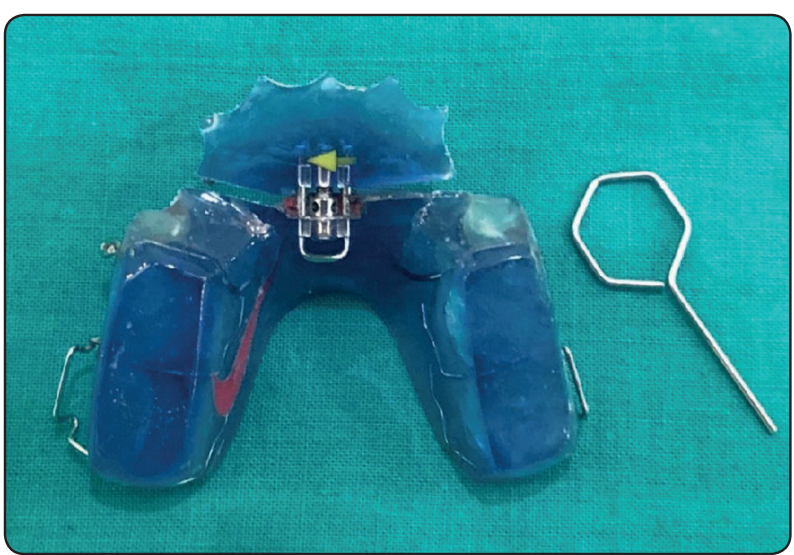

Fig. (5): Anterior screw with posterior bite plane

The children (and their parents/guardians) were instructed to :

1- Activate the screw two times per week $(0.5 \mathrm{~mm})$ until normal incisor relationship and overjet was obtained.

2- To firmly wear the appliance full time (day and night) except for meal times, teeth brushing, and during physical activities.

These instructions were explained and informed to the children (and their parents/guardians) again during every subsequent monthly appointment.

\section{B-Speech Evaluation:}

Speech evaluation was done by a Phoniatrician who is experienced in the speech therapy of children. All children were subjected to the protocol of speech evaluation and assessment applied in Phoniatric unit,
Faculty of Medicine, Benha University. The mother tongue of all of the subjects was Arabic, and they had no speech problems and had normal hearing without any history of nasal nor pharyngeal surgery.

\section{1-Articulation Test}

The Arabic Ain Shams Articulation test (24,25) was applied to all children. The test covered all phonemes that appear in the colloquial dialect in different positions (initial, middle, final) of the words.

\section{2-Auditory perceptual assessment for speech in- telligibility}

This Arabic speech intelligibility test was designed to assess the speech intelligibility in children objectively. This tool consisted of fifty pictures. The authors repeated the picture twice to produce one hundred cards. The cards are divided into three groups. The groups were different from each other in the phonological and the articulation structure especially in the type of initial consonant.

(1) The $1^{\text {st }}$ group was consisted of forty cards (twenty cards repeated twice) started by frontal articulated consonants.

(2) The $2^{\text {nd }}$ group was consisted of forty cards (twenty cards repeated twice) started by back articulated consonants resembling monosyllabic words and each picture name start by back articulated sounds.

TABLE (I) : Categorical classification of the scores:

\begin{tabular}{|c|c|c|c|}
\hline $\begin{array}{c}\text { Score of } \\
\text { subjective test }\end{array}$ & $\begin{array}{l}\text { \% Range of the Arabic } \\
\text { speech Intelligibility test }\end{array}$ & $\begin{array}{l}\text { Grade } \\
\text { Number }\end{array}$ & $\begin{array}{l}\text { Degree of Speech Intelligibility } \\
\text { (Severity) }\end{array}$ \\
\hline 1 & $0-29 \%$ & Grade I & Unintelligible speech (Speech is completely un- intelligible) \\
\hline 2 & $30-50 \%$ & Grade 2 & $\begin{array}{l}\text { Poor intelligibility (Speech is very difficult to be under- } \\
\text { stood; only isolated words or phrases are intelligible). }\end{array}$ \\
\hline 3 & 51- $66 \%$ & Grade 3 & $\begin{array}{l}\text { Fair intelligibility (The listener can understand with diffi- } \\
\text { culty about halfthe content of the message) . }\end{array}$ \\
\hline 4 & $67-84 \%$ & Grade 4 & $\begin{array}{l}\text { Good intelligibility (Speech is intelligible with exception of } \\
\text { a few words or phrases). }\end{array}$ \\
\hline 5 & $85-100 \%$ & Grade 5 & Excellent intelligibility (Speech is completely intelligible. \\
\hline
\end{tabular}


(3) The $3^{\text {rd }}$ group was consisted of twenty cards (ten cards repeated 2 times) resembling ten sentences were containing simple verbs.

Before applying this tool, the examiner administered the test after changing the order of cards in each group by shuffling. The examiner showed the cards to the examined child one by one. The child mission was to say the name of the picture in the presented card. The examiner wrote immediately what he heard from the child without any modifications in the prepared response sheet.

The Arabic speech intelligibility test estimated the grade of children speech intelligibility in percentage.

The examiner could predict roughly the intended word said by the child, but he/she could not decide which it was exactly. The evaluation of the child how to speak was not the target but the understandability of the child speech is the main concern.

The Arabic speech intelligibility test provided us by an objective estimation of the child speech intelligibility in percentage. The outcome of specific treatment strategy or surgical intervention was evaluated by this test as a good prognostic and comparative tool. The test assessed the speech intelligibility in progressing grades as described in table (I).

\section{Statistical analysis:}

Categorical data were presented as frequencies (n) and percentages (\%). Intergroup comparisons were done utilizing Fisher's exact test, while intragroup comparisons were done utilizing Cochran's Q tests followed by Dunn's post hoc test. Numerical data were presented as mean, standard deviation (SD) values. Data were explored for normality by checking the data distribution, calculating the mean and median values and using Kolmogorov-Smirnov and Shapiro-Wilk tests.
Parametric data were analyzed using independent t-test. Ordinal data were analyzed using Mann Whitney $U$ test for intergroup comparisons and Freidman's test of repeated measures followed by multiple pairwise comparisons utilizing Wilcoxon signed rank test with Benferroni correction for intragroup comparisons. The significance level was set at $\mathrm{p} \leq 0.05$ within all tests. Statistical analysis was performed with IBM ${ }^{\circledR}$ SPSS $^{\circledR}$ Statistics Version 26 for Windows.

\section{RESULTS}

\section{1- Results of articulation test}

1- Before appliance insertion, all sounds were intact for the majority of the cases $42(84 \%)$. Immediately after insertion, all the cases had difficulty in producing /s/, /s. /, /z/ sounds.

2- After one week of insertion, majority of the cases $30(60 \%)$ still had difficulty in producing the aforementioned letters.

3- After one month of insertion, most of the cases $40(80 \%)$ had no problem in producing different sounds. A significant difference was found between the speech status in different followup intervals $(\mathrm{p}<0.001)$. Pairwise comparisons, showed patients' speech prior to device insertion to be significantly different from other followup intervals except for one month after insertion $(\mathrm{p}<0.001)$.

4- In addition, a significant difference between speech status immediately after insertion and after one month $(<0.001)$. Table (II) and Figure (6).

Different superscript letters indicate a statistically significant difference within the same horizontal row*; significant ( $\mathrm{p} \leq 0.05) \mathrm{ns}$; non-significant $(\mathrm{p}>0.05)$ 


\section{2-Results of speech intelligibility test:}

There was a significant difference between values measured at different follow-up intervals $(\mathrm{p}<0.001)$. Pairwise comparisons showed value measured immediately after insertion $(87.20 \pm 2.92)$ to be significantly lower than values measured at different follow-up intervals $(\mathrm{p}<0.001)$. Speech intelligibility results were summarized in tables (III) and (IV) and figure (7).

Different superscript letters indicate a statistically significant difference within the same horizontal row*; significant $(\mathrm{p} \leq 0.05) \mathrm{ns}$; non-significant $(\mathrm{p}>0.05)$

TABLE (II): Frequency (n) and percentage (\%) values for articulation test:

\begin{tabular}{|c|c|c|c|c|c|c|}
\hline \multicolumn{2}{|c|}{ Articulation test } & $\begin{array}{c}\text { Pre-appliance } \\
\text { insertion }\end{array}$ & $\begin{array}{c}\text { Immediately after } \\
\text { appliance insertion }\end{array}$ & $\begin{array}{c}\text { One week after } \\
\text { appliance }\end{array}$ & $\begin{array}{c}\text { After one } \\
\text { month }\end{array}$ & p-value \\
\hline $\begin{array}{c}\text { All sounds are } \\
\text { intact }\end{array}$ & $\mathrm{n}$ & 42 & 0 & 20 & 40 & \\
\cline { 2 - 7 } & $\%$ & $84.0 \%$ & $0.0 \%$ & $40.0 \%$ & $80.0 \%$ & $<0.001 *$ \\
\hline $\begin{array}{c}\text { All sounds are intact except } \\
\text { / s/, / s./, /z/ become inter- } \\
\text { dental (9) }\end{array}$ & $\mathrm{n}$ & 8 & 50 & 30 & $20.0 \%$ & \\
\cline { 2 - 7 } & $16.0 \%$ & $100.0 \%$ & $60.0 \%$ & 20 \\
\hline
\end{tabular}

TABLE (III): Descriptive statistics for speech intelligibility:

\begin{tabular}{|c|c|c|c|c|}
\hline Time & Mean & SD & Median & Range \\
\hline Pre appliance insertion & 98.40 & 3.74 & 100.00 & 10.00 \\
\hline Immediately after appliance insertion & 87.20 & 2.92 & 85.00 & 10.00 \\
\hline One week after appliance & 96.00 & 3.23 & 95.00 & 10.00 \\
\hline After one month & 98.60 & 3.39 & 100.00 & 10.00 \\
\hline
\end{tabular}

TABLE (IV): Mean \pm Standard deviation (SD) values for speech intelligibility:

\begin{tabular}{|c|c|c|c|c|}
\hline $\begin{array}{c}\text { Pre - applianc } \\
\text { insertion }\end{array}$ & $\begin{array}{c}\text { Immediately after } \\
\text { appliance insertion }\end{array}$ & $\begin{array}{c}\text { One week } \\
\text { after appliance }\end{array}$ & $\begin{array}{c}\text { After one } \\
\text { month }\end{array}$ & p-value \\
\hline $98.40 \pm 3.74 \mathrm{~A}$ & $87.20 \pm 2.92^{\mathrm{B}}$ & $96.00 \pm 3.23^{\mathrm{A}}$ & $98.60 \pm 3.39^{\mathrm{A}}$ & $<0.001^{*}$ \\
\hline
\end{tabular}

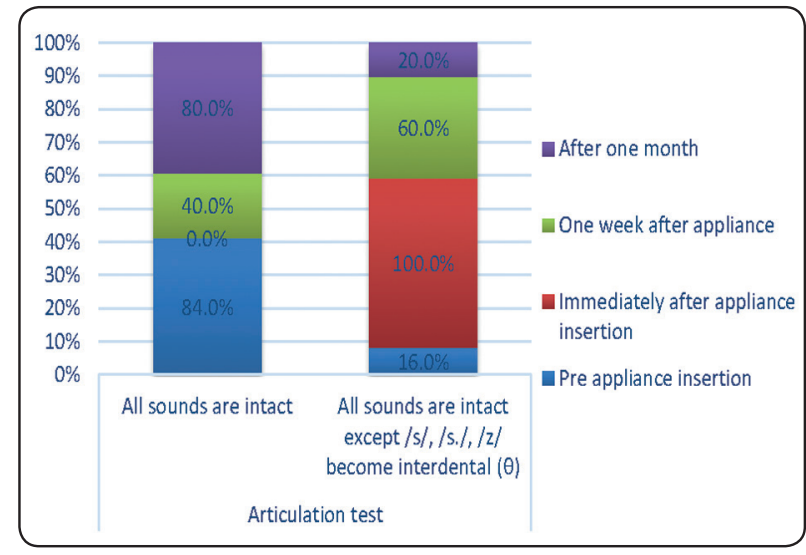

Fig. (6): Bar chart showing results of articulation test

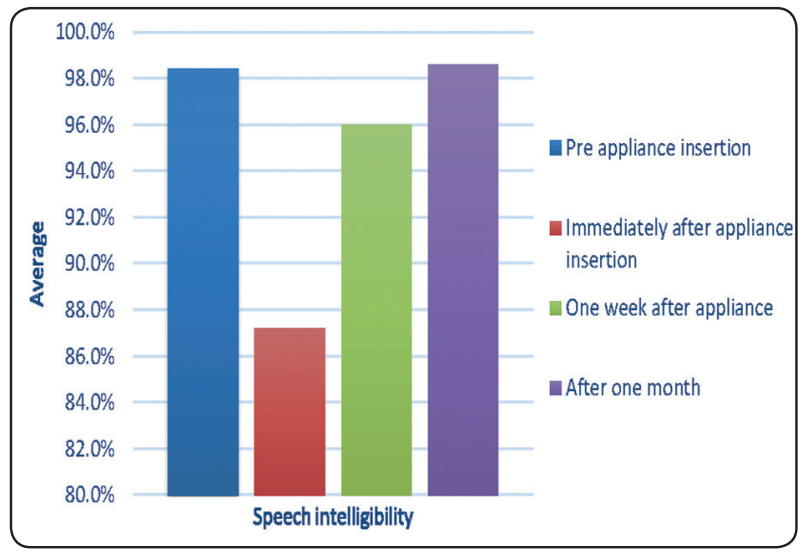

Fig. (7): Bar chart showing average values for speech intelligibility 


\section{DISCUSSION}

The individuals undergoing orthodontic treatment should be informed that the orthodontic appliances could produce some risks and discomforts such as affecting the speech intelligibility. The types of sound error that may occur, and the period of time during which the errors may exist should also be explained to the patients especially the professional adults ones that are seeking orthodontic treatment. For these reasons, it is important for the orthodontist to understand and to determine the possible risk factors affecting communication integrity.

Orthodontic appliances are foreign bodies in oral cavity and thus necessarily interfere with speech articulation especially removable ones due to their effects on tongue posture and palatal volume ${ }^{(19)}$.

The aim of the current study was to evaluate the effect of one removable anterior expansion screw with posterior bite planes on the speech quality and intelligibility.

Fifty children were chosen for this study at middle of mixed dentition stage with mean age of $(9.36 \pm 0.99)$ years to make sure that all the speech sounds had been completely developed. All children were suffering from dental anterior crossbite and were planned to be corrected with removable anterior expansion screw.

Before appliance insertion, all sounds were intact for the majority of the cases $42(84 \%)$, while for 8 $(16 \%)$ patients some speech sounds were unclear before appliance insertion which could be due to the effect of the malocclusion itself.

Immediately after insertion, all the cases had difficulty in producing /s/, /s. /, /z/ sounds which could be attributed to the fact that oral appliances could cause differences in speech production, usually affecting tongue posture and palatal volume.

After one week of appliance insertion, majority of the cases $30(60 \%)$ still had difficulty in producing the above mentioned letters, and then after one month of insertion, most of the cases $40(80 \%)$ had no problem in producing different sounds.

The results of our current study were in agreement with Rai et al. ${ }^{(7)}$ who evaluated and compared the duration of speech changes between two groups (labial and lingual orthodontics appliances). Speech evaluation was performed by two speech professionals (using an objective spectrographic, semiobjective auditive analysis) and four laypersons. (using subjective auditive evaluation). The tests were performed four times :

T1 (before appliances), T2 (within $24 \mathrm{~h}$ ), T3 (after 1 week) and T4 (after 1-month) of the start of therapy. They found that the speech performance in both groups was worst at 24 hour and 1 week and improved after 1 month.

The results of the current study were in agreement also with that of De Felippe et al. ${ }^{(10)}$ and that of Haydar et al $^{\left({ }^{(4)}\right.}$ who studied the effect of palatal expander on speech and concluded that regardless of the type of expander, most patients initially felt oral discomfort, and had problems with speech especially during the first week after cementation of the device. While, by the end of the first week remarkable adaptation was observed to all the devices.

The results of the current study were not in agreement with that of Kayıke et al. (25) who studied the effect of Hawley retainers on speech and found statistically significant speech disturbances in consonants [s] and [z] and also was not in accordance with that of Rai et al ${ }^{(5)}$ and Khattab et $\boldsymbol{a l} \boldsymbol{l}^{(6)}$ who studied the effects of the labial and lingual appliances on speech for thirty-four patients treated with either fixed lingual appliances or conventional fixed labial appliances. Speech performance was evaluated before, immediately after, one month after, and three months after brackets placement. They recorded a significant deterioration in articulation only immediately after brackets placement and 
improved after one month especially in labial brackets. Higher speech difficulties were recorded with the lingual brackets group after one month of placement $(\mathrm{P}<.001)$.

\section{CONCLUSIONS}

1- The speech performance while using removable anterior expansion screw for treatment of anterior dental crossbite was worst immediately after placement of the appliance and 1 week respectively.

2- The speech performance improved after one month of appliance insertion.

\section{REFERENCES}

1- Feu, D., de Oliveira, B.H., de Oliveira Almeida, M.A., Kiyak, H.A. and Miguel, J.A. Oral health-related quality of life and orthodontic treatment seeking. American Journal of Orthodontics and Dentofacial Orthopedics, 2010; 138, 152-159.

2- Papageorgiou, S.N., Gölz, L., Jäger, A., Eliades, T. and Bourauel, C. Lingual vs. labial fixed orthodontic appliances: systematic review and meta-analysis of treatment effects. European Journal of Oral Sciences, 2016; 124 , 105-118.

3- $\quad$ Long, H., Zhou, Y., Pyakurel, U., Liao, L., Jian, F., Xue, J., Ye, N., Yang, X., Wang, Y. and Lai, W. Comparison of adverse effects between lingual and labial orthodontic treatment: A systematic review. The Angle Orthodontist, 2013; 83, 1066-1073.

4- Haydar, B., Karabulut, G., Ozkan, S., Aksoy, A.U. and Ciğer, S. Effects of retainers on the articulation of speech. American Journal of Orthodontics and Dentofacial Orthopedics, 1996; 110,535-540.

5- Rai, A.K., Rozario, J.E. and Ganeshkar, S.V. Comparison of speech performance in labial and lingual orthodontic patients: A prospective study. Dental Research Journal, 2014; 11, 663-675.

6- Khattab, T.Z., Farah, H., Al-Sabbagh, R., Hajeer, M.Y. and Haj-Hamed, Y. Speech performance and oral impairments with lingual and labial orthodontic appliances in the first stage of fixed treatment: a randomized controlled trial. The Angle Orthodontist, 2012; 83, 519-526.
7- Rai, A.K., Ganeshkar, S.V. and Rozario, J.E. Parametric and non- parametric assessment of speech changes in labial and lingual orthodon- tics: A prospective study. APOS Trends in Orthodontics, 2013; 3, 99-109.

8- Eslamian, L. and Leilazpour, A.P. Tongue to palate contact during speech in subjects with and without a tongue thrust. European Journal of Orthodontics, 2006; 28, 475-479.

9- Araújo, E.A., Andrade, I., Jr, Brito, G.M., Guerra, L. and Horta, M.C. Perception of discomfort during orthodontic treatment with tongue spurs. Orthodontics, 2011; 12, 260 267.

10- De Felippe, N.L., Da Silveira, A.C., Viana, G. and Smith, B. Influence of palatal expanders on oral comfort, speech, and mastication. American Journal of Orthodontics and Dentofacial Orthopedics, 2010; 137, 48-53.

11- Stevens, K., Bressmann, T., Gong, S.G. and Tompson, B.D. Impact of a rapid palatal expander on speech articulation. American Journal of Orthodontics and Dentofacial Orthopedics, 2011 ; 140, e67-e75.

12- Atik, E., Aydınlı, F.E., Kayıkçı, M.E.K. and Ciğer, S. Comparing the effects of Essix and Hawley retainers on the acoustics of speech. European Journal of Orthodontics, 2016; doi:10.1093/ejo/cjw050.

13- Wan, J., Wang, T., Pei, X., Wan, Q., Feng, W. and Chen, J. Speech effects of Hawley and vacuum-formed retainers by acoustic analysis: A single-center randomized controlled trial. The Angle Orthodontist, 2017; 87, 286-292.

14- Stang, A. Critical evaluation of the Newcastle-Ottawa scale for the assessment of the quality of nonrandomized studies in meta-analyses. European Journal of Epidemiology, 2010;25, 603-605.

15- Da skalogiannakis, J., 2000. Glossary of Orthodontic Terms, First ed. Quintessence, Berlin. Dowsing, P., Sandler, P.J., 2004. How to effectively use a 2 x 4 appliance. J. Orthod. 31 (3), 248-258

16- McNamara Jr., J.A. Early intervention in the transverse dimension: is it worth the effort? Am. J. Orthod. Dentofacial Orthop,2002; 121 (6), 572-574.

17- Croll, T.P. Fixed inclined plane correction of anterior cross bite of the primary dentition. J. Pedod,1984, 9 (1), 84-94.

18- Bayrak, S., Tunc, E.S. Treatment of anterior dental crossbite using bonded resin-composite slopes: case reports. Eur. J. Dent, 2008;2 (4), 303-306. 
19-Giancotti,A., Mozzicato, P. and Mampieri, G. An alternative technique in the treatment of anterior cross bite in a case of Nickel allergy: a case report. Eur. J. Paediatr. Dent,2011; 12 (1), 60-62.

20- Bjerklin, K., Follow-up control of patients with unilateral posterior cross-bite treated with expansion plates or the quad-helix appliance. J. Orofac. Orthop, 2000 ; 61 (2), 112-124.

21- Littlewood, S.J., Tait, A.G., Mandall, N.A. and Lewis, D.H.. The role of removable appliances in contemporary orthodontics. Br. Dent. J,2001;191 (6), 304-306, 309-310.

22- Kulak M.E., Akan S, Ciger S and Ozkan S. Effects of Hawley retainers on consonants and formant frequencies of vowels. Angle Orthod. 2012;82:14-21.

23- Gizem Y, Bascıftc1 F.A., and Ozturk K. "The effects of rapid maxillary expansion on voice function." The Angle Orthodontist 87.1 (2017): 49-55.

24- Kotby M.N., Bassiouny S., El-Zomor M., and Mohsen E. Pilot study for standardization of an articulation test. Published in Proc $10^{\text {th }}$ Annual Ain Shams Medical Congress, Cairo, 1985.

25- Bassiouny S.E., Hegazi h.M., Nassar F.J., Ibrahim M.A., Saber A.S and Hamid A.A. : Development of an Arabic speech intelligibility test for children. The Egyptian Journal of Otolaryngology, 2013; 29:202-206. 